\title{
Are Boys More Aggressive than Girls after Playing Violent Computer Games Online? An Insight into an Emotional Stroop Task
}

\author{
Jingjin Tian ${ }^{1 *}$, Zhang Qian ${ }^{1,2,3 * \#}$ \\ ${ }^{1}$ School of Applied Technology, Southwest University, Chongqing, China \\ ${ }^{2}$ Department of Psychology, Southwest University, Chongqing, China \\ ${ }^{3}$ Center for the Study of Mental Health Education, Southwest University, Chongqing, China \\ Email: ”9114978@qq.com, zhq@swu.edu.cn
}

Received November $9^{\text {th }}$, 2013; revised December $8^{\text {th }}$, 2013; accepted January $4^{\text {th }}$, 2014

Copyright (C) 2014 Jingjin Tian, Zhang Qian. This is an open access article distributed under the Creative Commons Attribution License, which permits unrestricted use, distribution, and reproduction in any medium, provided the original work is properly cited. In accordance of the Creative Commons Attribution License all Copyrights (C) 2014 are reserved for SCIRP and the owner of the intellectual property Jingjin Tian, Zhang Qian. All Copyright (C) 2014 are guarded by law and by SCIRP as a guardian.

\begin{abstract}
The study was to examine the gender differences in aggression among Chinese children after playing violent computer games by using emotional STROOP task. 98 children participated in this study, with 49 assigned to violent computer game group and the other 49 assigned to nonviolent computer game group. The results demonstrated that there were significant differences in main affect of game type, and significant Game Type $\times$ Gender interaction as well. In particular, boys’ aggression was significantly impacted by violent games, whereas girls' aggression was not significantly impacted by violent games. The implication of this research is that, the significant difference in aggression to gender is activated, and that boys were more aggressive and sensitive to violent games than girls.
\end{abstract}

Keywords: Boys; Girls; Violent Computer Games; Children

\section{Introduction}

Considerable researches reported that media violence influenced aggressive cognition, aggressive affect, aggressive thoughts, physiological arousal, and aggressive behavior (Anderson, 1997; Anderson \& Bushman, 2002; Bushman, 2013; Geen \& O’Neal, 1969; Huesmann, 1986; Huesmann, Eron, Lefkowitz, \& Walder, 1973; Huesmann, Moise, Podolski, \& Eron, 2003). Some researchers asserted that aggression was a type of explicit behavior intended to harm another individual who was motivated to avoid that harm, and it was not an unclear affect, emotion or thought (Anderson \& Bushman, 2002). Other experts, however, argued that human aggression was a kind of attacking cognition, affect and behavior directed toward another individual (Baron \& Richardson, 1994; Geen, 2001). In our point of view, we tend to consider aggression as an intentional behavior to harm others based on aggressive cognition, affect and thought.

As for the association between violent computer games and subsequent aggression, former researchers held the view that playing violent video games would increase aggressive behavior through meta-analysis (Anderson et al., 2010; Ferguson, 2007; Anderson, Gentile, \& Buckley, 2007). For instance, it was suggested rewarding violent video games playing increases aggressive behavior by aggressive thinking (Carnagey \&

*The authors (Dr. Qian Zhang \& Jingjin Tian) contributed equally to the manuscript, so they are both the first author.

${ }^{\#}$ Corresponding author.
Anderson, 2005; Uhlmann \& Swanson, 2004; Barlett, Anderson, \& Swing, 2009; Zhen, Xie, Zhang, Wang, \& Li, 2011). Additionally, effects of reward and punishment given to video game violence are significant among college males (Ballard \& Lineberger, 1999). Experts also examined reward and punishment behavior among males following video game playing, it was showed that females were punished significantly more stringently as game violence increased, but this finding should be interpreted with caution (Ballard \& Robert, 1999). What's more, it did reveal that exposure to violent video games increases physiological arousal and hostile feelings and decreases prosocial behavior (Anderson \& Bushman, 2001). Some researchers examined the cause-effect relationship between exposure to firearm violence and subsequent perpetration of serious violence, and it was indicated that exposure to firearm violence approximately doubled the probability that an adolescent will perpetrate serious violence over the subsequent 2 years (Bingenheimer, Brennan, \& Earls, 2005). There was a significant association between the time spent watching television and the likelihood of subsequent aggressive acts by controlling previous aggressive behavior, childhood neglect, family income, neighborhood violence, parental education and psychiatric disorders (Johnson, Cohen, Smailes, Kasen, \& Brook, 2002). Evidence was steadily accumulating that prolonged exposure to violent TV programming during childhood is associated with subsequent aggression (Anderson \& Bushman, 2002; Zhang, Zhang, \& Wang, 2013; Zhang, Zhong, \& Zhang, 2013). The evidence strongly suggested that exposure to violent video 
games was a causal risk factor for increased aggressive behavior, cognition and affect and for decreased empathy and prosocial behavior (Anderson et al., 2010). Other researchers, however, argued although preference for violent media was correlated with aggressive behavior, no evidence indicated viewing violence in natural settings caused an increase in subsequent aggressiveness and some other factors (status hierarchy, trait aggressiveness, higher academic level) required to be investigated (Freedman, 1984, 1986, 2003; Garandeau, Ahn, \& Rodkin, 2011; Bushman, 1995).

Nowadays, more and more Chinese children spent plenty of time playing violent games in computer. Some of them were prone to solving problems resorting to aggression like the violent image within the virtual games. Consequently, imitated aggression caused by violent computer games exerted a negative impact on mental health for Chinese children such as aggression, and ultimately may even cause anti-social and crime behavior. A developmental theory was proposed to account for the relation between exposure to media violence and increased aggressive behavior. It was concluded that a bidirectional causal relation between media violence and aggression, and the findings could be generalized to real-world violence (Friedrich \& Huston, 1986). Nevertheless, a notable feature of the existing researches was the gender difference in aggression after exposure to media violence, which was unclear up till now. Some researchers explored sex differences in processing words relating to acts of direct and indirect aggression. Males demonstrated a perceptual bias for words relating to acts of direct aggression, taking significantly longer to correctly color name direct aggression words (Craig, Browne, Beech, \& Stringer, 2006; Cross, \& Campbell, 2012; Ramirez, Andreu, \& Fujihara, 2001; Smith, \& Waterman, 2005). Females were slower to correctly color name indirect aggression words. It was observed that a high level of physical aggression was the best predictor of bias in both males and females (Smith \& Waterman, 2005).

Although fierce debates existed among scientists as to the correlation between media violence and aggression of children, gender difference in aggression caused by media violence (violent games) was unresolved. Thus, the present study attempted to examine whether significant differences existed in aggression among boys and girls after exposing violent computer games by employing emotional Stroop task. Specifically, we sought to examine the gender differences in aggression among Chinese children after playing violent computer games. Based on prior researches and research rationale, we hypothesized that boys were more aggressive than girls by playing violent computer games than by playing non-violent computer games.

\section{Method}

\section{Participants}

98 Chinese children from a primary school from Southwest area participated in the study. Their age was ranged from 12 to $21(M=16.21, S D=1.62) .49$ children playing VIRTUAL COP2 (Personal Shooting) were regarded as violent game group, and 49 children playing FIGHT LANDLORD (Card Game) were deemed as nonviolent game group. The study was ethically approved by the Academic Committee from the Department of Psychology at Southwest University in China. All participants were treated according to the ethical guidelines of the American Psychological Association (APA, 2013).

\section{Experimental Design}

Multi-factor design was used, with game type and gender as independent variables and aggression as dependent variable. 2 (Game Type: violent vs. non-violent) $\times 2$ (Goal Word: aggressive vs. non-aggressive) $\times 2$ (Gender: boy vs. girl) repeated three measures analysis of variance (ANOVA) was conducted with game type and gender as between-group factor, and goal word as within-group factor.

\section{Instruments}

\section{Computer Games}

Since some children may rarely expose to computer games, the selection of computer games was moderate in difficulty. In addition, we choose computer games which were not played by participants to avoid the familiarity of computer games (Someone was needed to exclude if he or she once played this type of game). Based on this, VIRTUAL COP2 (Personal Shooting) and FIGHT LANDLORD (Card Game) were selected as the stimuli and materials in the study. Specifically, VIRTUAL COP2 required players to kill the gangsters by shooting with a blooding screen (language attack and body-fighting content), which was in line with the definition of violent video games (Anderson \& Bushman, 2001). FIGHT LANDLORD demanded players to strive for higher score than other players to achieve victory without any violent scene and blooding image (body-fighting content and language attack), which was complied with the definition of nonviolent video games (Anderson \& Bushman, 2001). The playing time of each game lasted for roughly 15 minutes.

\section{Computer}

The computer resolution rate was $1366 \times 768$ pixel, and the refresh rate was $75 \mathrm{~Hz}$. The distance between participants and screen was around $60 \mathrm{~cm}$, the faces of participants were parallel with the screen, and their eyes were focused on the screen centre.

\section{Goal Words}

50 aggressive and 50 nonaggressive words were randomly matched. The words were used in NO. 72 black italics and presented in three colors (green, red, yellow) on screen centre with a gray background. The presented order of goal words was counterbalanced.

\section{Emotional Stroop Task Procedure}

Participants signed an inform consent before experiment, then they were randomly distributed to play violent or nonviolent games, after that they finished emotional Stroop task. They could terminate at any time if they felt uncomfortable. The Stroop task procedure was programmed by E-prime psychology software. Instructions told that the experiment was to test speed and accuracy of responses, and the goal words would be presented in different colors. If the word color was green, press " 1 " on keyboard; if the word color is red, press "2"; if the word color is yellow, press " 3 ”. Participants should react as quickly and accurately as possible to distinguish the word color rather than word meaning, then the next trial began. After instructions appeared, a sign "+" emerged on the screen center with the time of $300 \mathrm{~ms}$, then the goal words appeared on screen center for $1000 \mathrm{~ms}$. The inter-stimulus-interval (ISI) was from $200 \mathrm{~ms}$ to 
300 ms. After participants reported the word color, a blank screen would appear for $100 \mathrm{~ms}$, and the program entered into next trial. If participants did not respond in $1000 \mathrm{~ms}$, the program also entered into the next trial automatically. Meanwhile, accuracy rate and reaction time (RT) were recorded (Figure 1).

Practical session. 20 trials existed in practical session but did not appear in subsequent formal session. The program returned to practical session if the accuracy rate was below 80 percent. The session was to familiar participants with key pressing, and to counterbalance the distinction of the color and key pressing.

Formal session. The experiment was divided into 3 blocks, in which 40 trials and totally 120 trials were presented on average. 50 aggressive and 50 nonaggressive words were presented in one of three colors (green, red, yellow), and each word appeared only once in each block. Participants had a short rest among blocks, then the program entered into the next block. The mean accuracy rate of the participants was from 85 to 95 percent, and the data of wrong and missing reaction was excluded.

\section{Results}

\section{The Main Effect of Violent Movies on Aggression}

One-way analysis of variance (ANOVA) was carried out to examine the main effect of goal word on children's aggression (see Table 1).

Table 1 showed that a significant main effect of goal word was found in reaction time (RT), and the RT of aggressive word was significantly longer than that of nonaggressive word $(F=$ 4.36, $p<0.05)$.

\section{The Game Type $\times$ Gender Interaction}

In this study, we thought the RT of aggressive words was longer than that of nonaggressive words (compared to participants playing nonviolent games). Thus, we assumed each participant had an aggressively priming score (APS), which was RT values by subtracting nonaggressive words from aggressive words, and examined whether significant difference of APS found in group type (see Table 2).

Table 2 showed the average APS of experimental group (14 $\mathrm{ms}$ ) was higher than that of control group (1 ms) by playing violent games, Table 3 showed significant difference in main effect of game type on aggression $(F=0.58, p<0.05)$.

Multivariate analysis of covariance (MANCOVA) was carried out to examine whether significant difference was found in APS among independent variables. The results can be seen in Table 3.

Table 3 showed that there was significant difference in Game Type $\times$ Gender interaction $(F=4.89, p<0.01)$. Simple effect analysis showed the average APS of girls playing violent and nonviolent games were 5.88 and 10.57 , respectively, and no significant difference was found $(F=2.14, p>0.05)$. The average APS of boys playing violent and nonviolent games was 8.63 and -1.24 , respectively, and that the APS of boys playing violent games was significant higher than that of boys playing nonviolent games $(F=4.21, p<0.05)$. The results can be seen in Table 4.

\section{Discussion}

The study selected Chinese children as participants, which

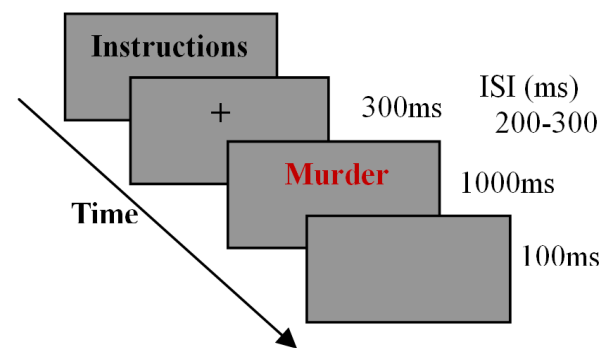

Figure 1.

Emotional stroop task.

Table 1.

RT differences between aggressive and nonaggressive words.

\begin{tabular}{cccccc}
\hline \multicolumn{5}{c}{ Goal Words } \\
\hline \multicolumn{5}{c}{ Aggressive Words Nonaggressive Words $F$} \\
RT & 548 & 52.95 & 532 & 52.04 & $4.36^{*}$ \\
\hline Note ${ }^{*} p<0.05 \cdot{ }^{* *} p<0.01 ;{ }^{* * *} p<0.001$ & &
\end{tabular}

Table 2.

APS differences between violent game and nonviolent game group.

\begin{tabular}{ccccccc}
\hline & Group Type & Aggressive & Non-aggressive & \multicolumn{2}{c}{ APS } & \\
\hline \multirow{4}{*}{ Violent } & $M$ & $S D$ & $M$ & $S D$ & \\
Nonviolent & 558 & 50.26 & 534 & 47.95 & +14 \\
\hline
\end{tabular}

Note: APS-aggressively priming score (mean RT values of aggressive words minus nonaggressive words).

Table 3.

MANCOVA for Game Type, Game Type $\times$ Gender interaction in APS.

\begin{tabular}{cccc}
\hline Variables & $M$ & $S D$ & $F$ \\
\hline Game Type & 225 & 26.55 & $0.58^{*}$ \\
Movie Type $\times$ Gender & 1125 & 125.06 & $4.89^{* *}$
\end{tabular}

Note: ${ }^{*} p<0.05 ;{ }^{* *} p<0.01 ;{ }^{* * *} p<0.001$.

Table 4.

The comparison between boys and girls in APS.

\begin{tabular}{cccc}
\hline Gender & Violent Game & Nonviolent Game & $F$ \\
\hline Boys & 8.63 & -1.24 & $4.21^{*}$ \\
Girlsr & 5.88 & 10.57 & 2.14 \\
\hline
\end{tabular}

Note: ${ }^{*} p<0.05 ;{ }^{* *} p<0.01 ;{ }^{* * *} p<0.001$.

was different from prior researches (Bushman, 1995). In addition, we used emotional Stroop task to explore the gender differences in effects of violent computer games on aggression among children. It was showed that significant difference in main effect of game type on aggression among children, and that significant Game Type $\times$ Gender interaction was found, particularly aggression was significantly activated by violent games only among boys, but not among girls. Based on this, we inferred that boys may play more violent games than girls, thus leading to rapid development of their aggressively cognitive mechanisms. This result, to some extent, was consistent with our hypothesis that boys may be more aggressive than girls by playing violent games rather than nonviolent games. Therefore, boys on campus may be more prone to playing violent games 
than girls. In the present study, game types, goal words and gender were independent variables, which all significantly affected children's aggression, partly supporting Cognitive-new Association Model (CAM) and General Aggression Model (GAM) (Anderson, 2002; Berkowitz, 1990; Anderson, Anderson, \& Deuser, 1996). Additionally, boys were more likely to be activated by violent stimuli than girls, which replicated previous researches (Salmivalli \& Kaukiainen, 2004; Boutwell, Franklin, Barnes, \& Beaver, 2011; Lansford et al., 2012). Therefore, it could be assumed that repeated exposure to violent media may form aggressively cognitive structure for boys, and thus boys showed explicit aggressions. In conclusion, there were significant gender differences in aggression among children after playing violent computer games, and the boys showed more willingness to be aggressive and susceptible to violence than girls after viewing violent movies. Furthermore, the mechanism (e.g., culture, neuroscience) underlying the significant effects of violent computer games on aggression among Chinese children required psychologists to explore further.

\section{Acknowledgements}

The research was supported by the National Youth Grant of National Educational Science Planning Project in 2013 (CBA130128), and funded by a Youth Grant of Social Sciences and Humanities from the Ministry of Education in China (13YJC190030) as well as the Fundamental Research Funds for the Central Universities (SWU1409135). Writing of the paper was also supported by a scholarship from the China Scholarship Council (CSC) to Dr. Qian Zhang during his visit at University of Illinois at Urbana-Champaign (201308505040). Sincere gratitude should be given to the anonymous reviewers for their thoughtful feedback on this draft.

\section{REFERENCES}

American Psychological Association (2013). Publication Manual of the American Psychological Association (6th ed.). Washington, D.C.

Anderson, C. A., Gentile, D. A., \& Buckley, K. E. (2007). Violent video game effects on children and adolescents. New York: Oxford University Press.

http://dx.doi.org/10.1093/acprof:oso/9780195309836.001.0001

Anderson, C. A. (2010). Violent video game effects on aggression, empathy, and prosocial behavior in eastern and western countries: A meta-analytic review. Psychological Bulletin, 136, 151-173. http://dx.doi.org/10.1037/a0018251

Anderson, C. A. (1997). Effects of violent movies and trait hostility on hostile feelings and aggressive thoughts. Aggressive Behavior, 23, 161-178.

http://dx.doi.org/10.1002/(SICI)1098-2337(1997)23:3<161::AID-AB 2>3.0.CO;2-P

Anderson, C. A., Anderson, K. B., \& Deuser, W. E. (1996a). Examining an affective aggression framework: Weapon and temperature effects on aggressive thoughts, affect and attitudes. Personality and Social Psychology Bulletin, 22, 366-376. http://dx.doi.org/10.1177/0146167296224004

Anderson, C. A., \& Bushman, B. J. (2001). Effects of violent video games on aggressive behavior, aggressive cognition, aggressive affect, physiological arousal, and pro-social behavior: A meta-analytic review of the scientific literature. Psychological Science, 5, 353-359. http://dx.doi.org/10.1111/1467-9280.00366

Anderson, C., \& Bushman, B. J. (2002). Human aggression. Annual Review of Psychology, 53, 27-51.

http://dx.doi.org/10.1146/annurev.psych.53.100901.135231

Barlett, C. P., Anderson, C. A., \& Swing, E. L. (2009). Video game effects-confirmed, suspected, and speculative: A review of the evidence. Simulation Gaming, 40, 377-403. http://dx.doi.org/10.1177/1046878108327539

Ballard, M. E., \& Lineberger, R. (1999). Video game violence and confederate gender: Effects on reward and punishment given by college males. Sex Roles, 41, 541-558. http://dx.doi.org/10.1023/A:1018843304606

Ballard, M. E., \& Robert, L. (1999). Video game violence and confederate gender: Effects on reward and punishment given by college males. Sex Roles, 41, 541-558.

http://link.springer.com/article/10.1023\%2FA\%3A1018843304606\# page-1

Baron, R. A., \& Richardson, D. (1994). Human Aggression. New York: Plenum.

Berkowitz, L. (1990). On the formation and regulation of anger and aggression: A cognitive-neoassociationistic analysis. American Psychologist, 45, 494-503.

Bingenheimer, J. B., Brennan, R. T., \& Earls, F. J. (2005). Sociology: Firearm violence exposure and serious violent behavior. Science, 308, 1323-1326. http://dx.doi.org/10.1126/science.1110096

Boutwell, B. B., Franklin, C. A., Barnes, J. C., \& Beaver, K. M. (2011). Physical punishment and childhood aggression: The role of gender and gene-environment interplay. Aggressive Behavior, 37, 559-568. http://dx.doi.org/10.1002/ab.20409

Carnagey, N. L., \& Anderson, C. A. (2003). Theory in the study of media violence: The general aggression model. In D. A. Gentile (Ed.), Media violence and children: A complete guide for parents and professionals (pp. 87-105). Westport, CT: Praeger.

Craig, L. A., Browne, K. D., Beech, A., \& Stringer, I. (2006). Differences in personality and risk characteristics in sex, violent and general offenders. Criminal Behaviour and Mental Health, 16, 183-194. http://dx.doi.org/10.1002/cbm.618

Cross, C. P., \& Campbell, A. (2012). The effects of intimacy and target sex on direct aggression: Further evidence. Aggressive Behavior, 38, 272-280. http://dx.doi.org/10.1002/ab.21430

Ferguson, C. J., \& John, K. (2010). Much ado about nothing: The misestimation and over interpretation of violent video game effects in Eastern and Western nations: Comment on Anderson et al. (2010). Psychological Bulletin, 136, 174-178.

http://dx.doi.org/10.1037/a0018566

Freedman, J. L. (1984). Effect of television violence on aggressiveness. Psychological Bulletin, 96, 227-246.

http://dx.doi.org/10.1037/0033-2909.96.2.227

Freedman, J. L. (1986). Television violence and aggression: A rejoinder. Psychological Bulletin, 100, 372-378. http://dx.doi.org/10.1037/0033-2909.100.3.372

Freedman, J. L. (2003). Media violence and its effect on aggression: Assessing the scientific evidence. Toronto: University of Toronto Press. http://dx.doi.org/10.1037/0033-2909.96.2.227

Friedrich-Cofer, L., \& Huston, A. C. (1986). Television violence and aggression: The debate continues. Psychological Bulletin, 100, 364371. http://dx.doi.org/10.1037/0033-2909.100.3.364

Garandeau, C. F., Ahn, H. J., \& Rodkin, P. C. (2011). The social status of aggressive students across contexts: The role of classroom status hierarchy, academic achievement, and grade. Developmental Psychology, 47, 1699-1710. http://dx.doi.org/10.1037/a0025271

Geen, R. G., \& O’Neal, E. C. (1969). Activation of cue-elicited aggression by general arousal. Journal of Personality and Social Psychology, 11, 289-292. http://dx.doi.org/10.1037/h0026885

Huesmann, L. R. (1986). Psychological processes promoting the relation between exposure tomedia violence and aggressive behavior by the viewer. Journal of Social Issues, 42, 125-139. http://dx.doi.org/10.1111/j.1540-4560.1986.tb00246.x

Huesmann, L. R., Eron, L. D., Lefkowitz, M. M., \& Walder, L. O. (1973). Television violence and aggression: The causal effect remains. American Psychologist, 28, 617-620. http://dx.doi.org/10.1037/h0038223

Huesmann, L. R., Moise-Titus, J., Podolski, C. L., \& Eron, L. D. (2003). Longitudinal relations between children's exposure to TV violence and their aggressive and violent behavior in young adulthood: 1977-1992. Developmental Psychology, 39, 201-221. 
http://dx.doi.org/10.1037/0012-1649.39.2.201

Johnson, J. G., Cohen, P., Smailes, E. M., Kasen, S., \& Brook, J. S. (2002). Television viewing and aggressive behavior during adolescence and adulthood. Science, 295, 2468-2471. http://dx.doi.org/10.1126/science.1062929

Lansford, J. E., Skinner, A. T., Sorbring, E., Giunta, L. D., DeaterDeckard, K., Dodge, K. A., Malone, P. S., Oburu, P., Pastorelli, C., Tapanya, S., Uribe Tirado, L. M., Zelli, A., Al-Hassan, S. M., Peña Alampay, L., Bacchini, D., Bombi, A. S., Bornstein, M. H., \& Chang, L. (2012). Boys' and girls' relational and physical aggression in nine countries. Aggressive Behavior, 38, 298-308. http://dx.doi.org/10.1002/ab.21433

Ramirez, J. M., Andreu, J. M., \& Fujihara, T. (2001). Cultural and sex differences in aggression: A comparison between Japanese and Spanish students using two different inventories. Aggressive Behavior, 27, 313-322. http://dx.doi.org/10.1002/ab.1014

Salmivalli, C., \& Kaukiainen, A. (2004). Female aggression revisited: Variable- and person-centered approaches to studying gender differences in different types of aggression. Aggressive Behavior, 30, 158-163. http://dx.doi.org/10.1002/ab.20012

Smith, P., \& Waterman, M. (2005). Sex differences in processing ag- gression words using the emotional Stroop task. Aggressive Behavior, 31, 271-282. http://dx.doi.org/10.1002/ab.20071

Uhlmann, E., \& Swanson, J. (2004). Exposure to violent video games increases automatic aggressiveness. Journal of Adolescence, 27, 4152. http://dx.doi.org/10.1016/j.adolescence.2003.10.004

Zhang, Q., Zhang, D. J., \& Wang, L. X. (2013). Is aggressive trait responsible for violence? Priming effects of aggressive words and violent movies. Psychology, 4, 96-100.

http://dx.doi.org/10.4236/psych.2013.42013

Zhang, Q., Zhong, J. X., \& Zhang, D. J. (2013). Does violent movie exposure affect aggressive cognition of Chinese adolescents? Evidences from a modified STROOP task. International Journal of Psychological Studies, 5, 11-18. http://dx.doi.org/10.5539/ijps.v5n2p11

Zhen, S. J., Xie, H. L., Zhang, W., Wang, S. J., \& Li, D. P. (2011). Exposure to violent computer games and Chinese adolescents' physical aggression: The role of beliefs about aggression, hostile expectations, and empathy. Computers in Human Behavior, 27, 1675-1687. http://dx.doi.org/10.1016/j.chb.2011.02.006 